\title{
Job Demands and Resources Experienced by the Early Childhood Education Workforce Serving High-Need Populations
}

\author{
Charlotte V. Farewell $^{1}$ (D) . Jennie Quinlan ${ }^{1} \cdot$ Emily Melnick $^{1} \cdot$ Jamie Powers $^{1} \cdot$ Jini Puma $^{1}$
}

Accepted: 28 November 2020 / Published online: 5 January 2021

(C) The Author(s), under exclusive licence to Springer Nature B.V. part of Springer Nature 2021, corrected publication 2022

\begin{abstract}
The early childhood education (ECE) workforce plays a key role in promoting early childhood development by their interactions with young children during formative years. However, the inherent demands of the profession and the work conditions within ECE settings affect job satisfaction and overall health and well-being. This study applied the Job Demands-Resources Model (JD-R) and administered a cross-sectional survey $(n=137)$ to examine disparities in personal and external demands and resources that may impact job satisfaction and turnover rates among ECE staff who provide care for preschool children (3-5 years of age). ECE staff reported higher levels of personal demands, including depression and perceived stress, and external demands, including workload and staffing concerns, compared to the national workforce (all $p<.01)$. The data also illustrated disparities related to resource access; ECE staff reported lower levels of personal resources, including mindfulness, and less access to external resources including safety climate, resource adequacy, role clarity, respect, and management relationships (all $p<.01$ ). Only $34 \%$ of ECE staff reported being very satisfied with their work compared to $49 \%$ of the national workforce $(p<.01)$. External resources were significantly and positively associated with job satisfaction $(B=.09$, $p<.01)$. These findings suggest that ECE staff experience significantly higher demands and have access to significantly fewer resources in the workplace, and that bolstering job-related resources may translate to increased job satisfaction.
\end{abstract}

Keywords Early childhood education $\cdot$ Teachers $\cdot$ Well-being $\cdot$ Job satisfaction $\cdot$ Head start

\section{Introduction}

The early childhood years are a time of rapid growth and development for most fundamental skills. During these critical years, children develop the cognitive, language, motor, and social-emotional skills necessary to support a productive and happy life (O'Connor et al. 2018; Shonkoff 2010). The early childhood workforce plays a key role in promoting the development of these skills through their interactions with young children in their care during these formative years and by constructing environments that foster the healthy development of children in early childcare education (ECE) settings (Whitebook et al. 2016). The mental and physical health of ECE staff (e.g., lead teachers, assistant teachers, directors, administrators, family support staff) can either

Charlotte V. Farewell

charlotte.farewell@cuanschutz.edu

1 Rocky Mountain Prevention Research Center, Colorado School of Public Health, 13001 East 17th Place I Building 500 Rm E3353 I, Aurora, CO 80045, USA enhance or limit the interpersonal and physical engagement that staff have with the children in their care, which then impacts the children's overall development. Despite the importance of the health and well-being of those responsible for providing safe, stable, and nurturing environments for children, it is often overlooked.

Working in ECE settings is stressful. The inherent demands of the profession and the work conditions within ECE settings affect staff's psychological, emotional and physical health and well-being. Demands of the early childcare workforce, specifically those who care for children aged 3-5 years of age, include: low pay (the average yearly salary for an early educator is $\$ 21,000$ USD) (Linnan et al. 2017), poor working conditions, including long hours, high job demands (especially among directors and administrators), and low job control (with teachers and classroom workers reporting the lowest levels of job control) (Linnan et al. 2017). Additionally, ECE staff are at increased risk of infectious diseases due to close proximity to children who have less developed immune systems; increased risk of injury and falls due to lifting and moving children regularly; 
and increased risk of encountering environmental hazards, such as toxic cleaning materials and art supplies (Shuai et al. 2014). A systematic review of 30 nationwide studies found that these challenging work conditions are related to a high risk for injuries and other occupational hazards, as well as adverse effects on workers' psychological, emotional, and physical health (Bright and Calabro 1999; Cumming 2017; Gratz et al. 2002). The unfavorable work conditions in ECE settings play a role in the fact that ECE staff are disproportionately impacted by chronic mental and physical health conditions. For example, ECE staff have a higher prevalence of being overweight, obesity, heart disease and diabetes compared to the general population (Linnan et al. 2017; Sharma et al. 2013; Whitaker et al. 2013).

The national staff turnover rate for early educators is between 24 and 40\% annually in the United States (Totenhagen et al. 2016). Although poor compensation and lack of benefits have been cited as reasons for high turnover among ECE staff, studies have found that compensation alone is not an indicator of turnover and job satisfaction (Torquati et al. 2007; Wells 2015). Poor compensation coupled with external factors relating directly to the work environment, such as stressful demands and poor working conditions, may be predictors of job dissatisfaction and turnover rates (Torquati et al. 2007). For ECE staff working in Head Start settings, a federally funded preschool program in the United States which provides free care to low-income families with children 3-5 years of age, the demands may be particularly significant. Children in Head Start settings experience disproportionately high numbers of adverse early childhood experiences (ACEs), compared to the broader population of young children 3-5 years of age in the US. For example, one study found that among a sample of 628 preschool-aged children enrolled in Head Start, 63\% of parents reported that they experienced three or more ACEs and $40 \%$ of these children had already experienced three or more ACEs (Blodgett 2014). Given the additional challenges of working with this high need population, it is critical to understand how the demands and resources faced by this sample of ECE staff compare to the national workforce.

The authors applied the Job Demands-Resources Model (JD-R) to examine demands and resources that may impact job satisfaction among ECE staff serving Head Start populations. The JD-R model is used in occupational stress research to predict employee satisfaction, burnout and turnover in demanding professions (Bakker and Demerouti 2017). This model examines personal and external factors that relate to work demands and work resources, which may impact overall job satisfaction, turnover and burn-out (Dicke et al. 2018). Demands can include personal factors, such as poor mental health, and external factors including workload, staffing-related issues, and job stress. Resources are positive factors that help support job satisfaction and may mitigate turnover. Personal resources include mindfulness and resiliency, whereas external resources include role clarity, supervisory support, and respect. The JD-R model theorizes that poor job satisfaction and high burnout and turnover results from a lack of balance between these two categories (Bakker and Demerouti 2017; Demerouti et al. 2001). Figure 1 displays the application of the JD-R model and personal and external factors that are hypothesized to impact job satisfaction and turnover rates among ECE staff serving Head Start populations. This purpose of this study was to explore personal and external demands and resources that were related to the unique needs of the ECE population, compare these data to normative samples, and investigate how these demands and resources may impact job satisfaction. Findings may be used to inform strategies and policies to mitigate poor job satisfaction and high turnover rates experienced by ECE staff.

\section{Materials and Methods}

\section{Participants}

All ECE staff employed at Head Start-funded ECE centers that had established previous partnerships with the Culture of Wellness in Preschools (COWP) program were eligible to participate. Researchers at a large public university in the United States developed the COWP program in 2012. The goals of the multi-level, multi-component intervention are to increase fruit and vegetable consumption and the physical activity of preschool-aged children and their families. As of 2019, the COWP program had been implemented in 150 ECE centers serving roughly 48,000 low-income children and their caregivers in 14 counties in Colorado. The research team invited all ECE staff (e.g., teachers, directors, administrators, family support staff) who worked at Head Start-funded ECE centers in three urban counties in Colorado $(n=77 \mathrm{ECE}$ centers) to participate in an online survey to understand the demands and resources faced by ECE staff who serve high-need populations. The research team gathered eligible participants' emails from existing contacts or ECE directors.

\section{Procedure}

The Colorado Multiple Institutional Review Board (COMIRB) approved all procedures involved in this study. Participation was voluntary and data was kept confidential. According to the IRB, individual informed consent was not required for this study. In September of 2019, the research team sent an information sheet electronically to ECE directors of all eligible Head Start centers. This sheet noted that participation in the study was voluntary, that by answering 


\section{Personal Demands}

- Perceived Stress

- Poor Mental Health (Depression)

\section{External Demands}

- Workload

- Staffing

- Job Stress

\section{Personal Resources}

- Resiliency

- Mindfulness

\section{External Resources}

- Safety Climate

- Supervisory Behavior

- Role Clarity

- Resource Adequacy

- Teamwork

- Respect

- Trust

- Management Relationship

Fig. 1 Conceptual model depicting the application of the Job-Demands Resources Model to personal and external demands and resources that may impact job satisfaction and turnover rates among the Early Childhood Education workforce

the questionnaires consent was given, and that individual responses would be kept confidential and not shared with anyone other than key research personnel. Directors shared this information sheet with their staff.

Participants received an email invitation with a link to the electronic survey via REDCap in October of 2019. REDcap is a secure web-based platform for building and managing online databases and surveys approved by the COMIRB (funded by NIH/NCRR Colorado CTSI Grant Number UL1 TR002535) (Harris et al. 2009). Eligible participants received a total of four emails (one initial invitation and 3 subsequent reminders). The survey was enabled for data collection for a total of 3 weeks (October $4,2019-O c t o b e r 25,2019)$. The initial scheduled timeframe for survey participation was 22 weeks. However, researchers provided an extension of 1 week to increase participation rates. The survey took approximately $10 \mathrm{~min}$ to complete. Participants received an incentive of a $\$ 10$
Target gift card, which was delivered electronically within a month of survey completion.

Researchers sent email invitations with links to the electronic survey to 302 eligible ECE staff. Of these invitations sent, 140 surveys were completed. Researchers excluded three duplicate surveys from the sample. This resulted in a final analytic sample of 137 ECE staff surveys (45\%) from preschools representing 32 Head Start-funded ECE centers in three urban counties in Colorado.

\section{Instruments}

Multiple validated tools described below were included in the survey to assess personal and external demands and resources that may impact job satisfaction among ECE staff. 


\section{Personal Factors (Demands and Resources)}

Personal demands were evaluated using two measures including the: (1) Cohen Perceived Stress Scale (PSS) and (2) Patient Health Questionnaire (PHQ-8). The Cohen PSS is a validated tool and is designed to measure "the degree to which situations in one's life are appraised as stressful" (Cohen et al. 1983). The PSS consists of 10 questions measured with a 5-item likert scale. Example questions include, "In the last month, how often have you felt nervous and "stressed?" and "In the last month, how often have you felt confident about your ability to handle your personal problems?" The Patient Health Questionnaire-8 is a brief measure of depression. Using a cutoff score of $\geq 10$, the PHQ-8 has a sensitivity of $70 \%$ and a specificity of $98 \%$ in the general population for any depressive disorder (Kroenke et al. 2009). Sample questions include, "How often during the past 2 weeks were you bothered by little interest or pleasure in doing things." Personal resources were evaluated using two measures including the: (1) Brief Resilience Scale (BRS), and (2) Mindfulness Attention Awareness Scale (MAAS-5). The BRS is a 6-item reliable and valid tool for assessing resilience as the ability to bounce back or recover from stress (Smith et al. 2008). Sample questions include, "I tend to bounce back quickly after hard times" and "I have a hard time making it through stressful events." Finally, the MAAS-5 is a tool that includes 5-items related to mindfulness and shows high internal validity (MacKillop and Anderson 2007; Osman et al. 2016). This tool asks how frequently or infrequently they currently have each experience such as, "It seems I am "running on automatic, without much awareness of what I'm doing".

\section{External Factors (Demands and Resources)}

The Quality of Worklife (QWL) module was originally developed as a special section of the General Social Survey (GSS) which is administered through the National Data Program for Social Sciences at the University of Chicago (Quality of Worklife Questionnaire 2018). Researchers selected 20 items out of a total of 76 from the QWL module for this survey based on the relevance of the questions to demands and resources faced by the ECE workforce. Constructs assessed included 3-single item constructs related to demands (workload, job stress, staffing) and 8-single item constructs related to resources (safety climate, supervisory behavior, role clarity, resource adequacy teamwork, respect, trust, management relationship). All 76 questions from the QWL module were not included in the survey because of limited time and incentives available for survey completion, as well as limited relevance to the ECE workforce.

Worklife satisfaction was also assessed via the QWL question: "All in all, how satisfied would you say you are with your job?" Reponses were collected on a 3-item Likert scale (not satisfied, somewhat satisfied, very satisfied) and were dichotomized for regression analyses [not satisfied or somewhat satisfied (0), very satisfied (1)].

\section{Covariates}

The following demographic variables were included in the regression models: Ethnicity [not Hispanic (0), Hispanic (1)], education level [some college or less ( 0$)$, college degree (1)], and supervisory status [no (0), yes (1)]. Race and gender were not included in the models due to a lack of variation within the sample (75\% white, $92 \%$ under 59 years of age).

\section{Data Analysis}

Researchers exported data from REDCap into SPSS version 25 for analyses (IBM SPSS Inc. 2012). First, the authors ran univariate and bivariate analyses. Two-proportion $z$-tests were used to compare the sample responses (\%) with responses from the 2018 GSS national sample (national workforce) for the survey items that relate to external demands and resources (QWL survey). Two proportion $z$-tests (\%s) and independent sample $t$-tests (mean and standard deviations) were run to compare these data with nationally available normative data related to personal demands and resources (e.g., PHQ-8, BRS). The demographics of these normative samples vary due to the different normed scales currently available in the literature, Therefore, the comparisons should be interpreted cautiously. Alpha $(\alpha)$ was set at 0.01. A more conservative correction (e.g. Bonferroni) was not utilized to account for multiple comparisons because of the exploratory nature of this pilot study (Vasilopoulos et al. 2016).

To test the JD-R model, the authors ran two mixedeffects logistic regression models. The first model included a random ECE center effect to account for the clustering of associations between demands and resources (independent variables) and job satisfaction (dependent variable) among ECE staff within centers (Interclass Correlation Coefficients $(\mathrm{ICC})=.13$ ). First, personal demands (composite score of PHQ-8 and PSS; $m=22.06 ; \mathrm{SD}=10.35$; Range $=1-49$; Cronbach's $\alpha=.80$ ), external demands (composite score of 3-items; $m=6.38 ; \mathrm{SD}=1.69$; Range $=3-11$; Cronbach's $\alpha=.62$ ), personal resources (BRS and MAAS-5; $m=37.72$; $\mathrm{SD}=7.39$; Range $=17-55$; Cronbach's $\alpha=.51$ ) and external resources (composite score of 8-items; $m=32.44 ; \mathrm{SD}=3.89$; Range $=23-40$; Cronbach's $\alpha=.81$ ) were included in the model, controlling for covariates. Next, centered interaction terms between personal demands and resources and external demands and resources were added as potential moderators to assess if resources buffered associations between demands and job satisfaction. 


\section{Results}

Table 1 summarizes the demographic characteristics of the analytic sample, comprised of the 137 ECE staff members who completed the survey. Within the analytic sample, 52\% of respondents served in supervisory roles. Approximately a third (35\%) of respondents identified as Hispanic/Latino, $75 \%$ identified as white, $92 \%$ were between the ages of 18 and 59 years of age, and $70 \%$ of respondents possessed college degrees.

Table 2 displays (1) personal and external demands and resources and (2) overall job satisfaction among this analytic sample and nationally available normative data.

\section{Demands}

ECE staff reported higher levels of personal demands compared to nationally representative data. For example, in this sample, ECE staff scored higher on both the PHQ-8 and the PSS compared to the normative samples (Cohen et al. 1994; Kroenke et al. 2009); 20\% of ECE staff reported experiencing moderate or moderately severe depression compared to $8 \%$ of the national sample $(z=-4.6, p<.01)$ and on average, ECE staff scored $16.7(\mathrm{SD}=6.5)$ for perceived stress, which is significantly higher than the national average $(m=13.7$, $\mathrm{SD}=6.6 ; t(2522)=5.2, p<.01)$. ECE staff also reported significantly higher external demands, including workload

Table 1 Demographic characteristics of ECE staff included in analytical sample $(n=137)$

\begin{tabular}{ll}
\hline Variable & $n(\%)$ \\
\hline Supervisor & $65(51.5)$ \\
Yes & $69(48.5)$ \\
No & \\
Age & $119(92.2)$ \\
$18-59$ years & $10(7.8)$ \\
$60+$ years & \\
Race & $103(75)$ \\
White & $13(9.5)$ \\
Black & $6(4.4)$ \\
American Indian or Native American & $5(3.6)$ \\
Asian & $1(1.0)$ \\
Hawaiian/Pacific Islander & \\
Ethnicity & $45(35.2)$ \\
Hispanic & $83(60.6)$ \\
Non-Hispanic & \\
Education & $5(3.9)$ \\
High school graduate & $34(26.3)$ \\
Some college & $90(69.8)$ \\
College graduate &
\end{tabular}

and staffing concerns, compared to the national workforce. Approximately two-thirds (62\%) of ECE staff agreed or strongly agreed with the statement, "I have too much work to do everything well" compared to $35 \%$ within the national sample $(z=-6.5, p<0.01)$. Additionally, the majority of ECE staff $(82 \%)$ felt there were always, sometimes, or often not enough people or staff to get all the work done compared to $61.0 \%$ within the national sample $(z=-5.0, p<.01)$. However, responses related to job stress, or feeling used up at the end of the day, were not significantly different between these two groups $(z=1.9, p=.06)$.

\section{Resources}

Personal resources that may support job satisfaction of ECE staff were assessed in this sample. On average, ECE staff scored $3.6(\mathrm{SD}=0.7)$ on resiliency compared to normative data who scored $3.7(\mathrm{SD}=0.7)$ although these differences were not statistically significant $(t(979)=1.8$, $p=.07)$. This sample also reported significantly lower levels of mindfulness $(m=3.2, \mathrm{SD}=1.2)$ compared to normative data $(m=4.0, \mathrm{SD}=1.0)(t(1043)=7.9, p<.01) . \mathrm{ECE}$ staff reported significantly less access to specific external resources, including safety climate, resource adequacy, role clarity, respect, and management relationship, compared to the national workforce. For example, ECE staff were less likely to describe the safety and health conditions of their workplace as good $(z=3.2, p<.01)$, were less likely to report that conditions in their job allow them to be as productive as they could be $(z=-5.7, p<.01)$, were less likely to know exactly what is expected of them at work $(z=4.6$, $p<.01)$, and were less likely to report that at the place where they work, they are treated with respect $(z=3.4, p<.01)$ compared to the national workforce.

\section{Job Satisfaction}

These data suggest that there are differences in overall job satisfaction between this sample of ECE staff and the national workforce. Only 34\% of ECE staff reported being very satisfied with their work compared to $49 \%$ of the national workforce $(z=3.5, p<.01)$. Notably, in both samples less than $50 \%$ of survey respondents report being very satisfied with their jobs.

Table 3 presents results from the mixed-effects logistic regression models. Model 1 examined the association between demands, resources and job satisfaction after adjustment for the fixed effects of ethnicity, education, and supervision status, and the random effect of ECE center. Personal and external demands were not significantly associated with job satisfaction, holding all other variables in the model constant ( $p=.99, p=.51$, respectively). However, for each one unit increase in personal and external resources, individuals 
Table 2 Demands and resources among a sample of Head Start-employed early childhood education staff and nationally-representative samples

\begin{tabular}{|c|c|c|c|c|c|}
\hline Constructs & Survey item & ECE staff $(n=137)$ & National sample+ & $\begin{array}{l}z \text { Score }(\%) \text { or } \\
t \text {-test }(m(\mathrm{SD}))\end{array}$ & $p$ value \\
\hline \multicolumn{6}{|l|}{ Demands } \\
\hline \multicolumn{6}{|l|}{ Personal factors } \\
\hline & & $\mathrm{M}(\mathrm{SD})$ & $\mathrm{M}(\mathrm{SD})$ & & \\
\hline Mental health & Perceived Stress Scale (PSS) & $\begin{array}{l}16.7(6.5) \\
\% \text { PHQ-8 Score } \geq 10\end{array}$ & $13.7(6.6)$ & 5.2 & .00 \\
\hline Mental health & $\begin{array}{l}\text { Patient Health Questionnaire Depres- } \\
\text { sion Tool (PHQ-8) }\end{array}$ & 19.7 & 8.6 & -4.6 & .00 \\
\hline \multicolumn{6}{|l|}{ External factors } \\
\hline & & $\%$ agree or strongly agree & & & \\
\hline \multirow[t]{2}{*}{ Workload } & $\begin{array}{l}\text { I have too much work to do every- } \\
\text { thing well }\end{array}$ & 62.0 & 35.0 & -6.5 & .00 \\
\hline & & $\%$ very often or often & & & \\
\hline \multirow[t]{2}{*}{ Job stress } & $\begin{array}{l}\text { In the past month, how often have } \\
\text { you felt used up at the end of the } \\
\text { day? }\end{array}$ & 43.8 & 36.0 & 1.9 & .06 \\
\hline & & $\%$ always, often or sometimes & & & \\
\hline Staffing & $\begin{array}{l}\text { How often are there not enough peo- } \\
\text { ple or staff to get all the work done? }\end{array}$ & 81.8 & 61.0 & -5.0 & .00 \\
\hline \multicolumn{6}{|l|}{ Resources } \\
\hline \multicolumn{6}{|l|}{ Personal factors } \\
\hline & & $\mathrm{M}(\mathrm{SD})$ & $\mathrm{M}(\mathrm{SD})$ & & \\
\hline Resiliency & Brief Resilience Scale (BRS) & $3.6(0.7)$ & $3.7(0.7)$ & 1.8 & .07 \\
\hline Mindfulness & $\begin{array}{l}\text { Mindful Attention Awareness Scale } \\
\text { (MAAS) }\end{array}$ & $3.2(1.2)$ & $4.0(1.0)$ & 7.9 & .00 \\
\hline \multicolumn{6}{|l|}{ External factors } \\
\hline & & $\%$ agree or strongly agree & & & \\
\hline Safety climate & $\begin{array}{l}\text { The safety and health conditions } \\
\text { where I work are good }\end{array}$ & 89.0 & 95.0 & 3.2 & .00 \\
\hline Supervisory behavior & $\begin{array}{l}\text { The place where I work is run in a } \\
\text { smooth and effective manner }\end{array}$ & 69.4 & 78.0 & 2.4 & .02 \\
\hline \multirow[t]{2}{*}{ Resource adequacy } & $\begin{array}{l}\text { Conditions in my job allow me to be } \\
\text { as productive as I could be }\end{array}$ & 72.2 & 88.0 & -5.7 & .00 \\
\hline & & $\%$ always, often or sometimes & & & \\
\hline Role clarity & $\begin{array}{l}\text { On my job, I know exactly what is } \\
\text { expected of me }\end{array}$ & 86.2 & 95.0 & 4.6 & .00 \\
\hline Teamwork & $\begin{array}{l}\text { How often do you take part with } \\
\text { others in making decisions that } \\
\text { affect you? }\end{array}$ & 81.7 & 75.0 & -1.8 & .07 \\
\hline Respect & $\begin{array}{l}\text { At the place where I work, I am } \\
\text { treated with respect }\end{array}$ & 85.4 & 93.0 & 3.4 & .00 \\
\hline \multirow[t]{2}{*}{ Trust } & $\begin{array}{l}\text { I trust the management at the place } \\
\text { where I work }\end{array}$ & 78.1 & 82.0 & 1.2 & .24 \\
\hline & & $\%$ very good or quite good & & & \\
\hline Management relationship & $\begin{array}{l}\text { In general, how would you describe } \\
\text { the relations in your workplace } \\
\text { between management and employ- } \\
\text { ees? }\end{array}$ & 57.0 & 71.0 & -3.6 & .00 \\
\hline \multicolumn{6}{|l|}{ Overall job satisfaction } \\
\hline & & $\%$ very satisfied & & & \\
\hline Job satisfaction & & 34.3 & 49.0 & 3.5 & 0.00 \\
\hline
\end{tabular}

+ Sample sizes: 2387 [PSS (Cohen et al. 1994)]; 198,678 [PHQ-8 (Kroenke et al. 2009)]; 908 [MAAS (Osman et al. 2016)]; 844 [BRS (Smith et al. 2008)]; and QWL constructs [range from 5876 to 8994 depending on question (Smith et al. 2019)] 
Table 3 Mixed-effects logistic regression model of factors related to job satisfaction of ECE staff $(n=137)$

\begin{tabular}{|c|c|c|c|}
\hline Characteristic & Odds ratio & $95 \% \mathrm{CI}$ & \\
\hline & & Lower limit & Upper limit \\
\hline \multicolumn{4}{|l|}{ Model 1} \\
\hline Personal demands & .99 & .94 & 1.07 \\
\hline External demands & .89 & .62 & 1.27 \\
\hline Personal resources & $1.10^{*}$ & 1.01 & 1.20 \\
\hline External resources & $.1 .57 * *$ & 1.26 & 1.94 \\
\hline \multicolumn{4}{|l|}{ Ethnicity } \\
\hline Not Hispanic & - & - & - \\
\hline Hispanic & 1.26 & .39 & 4.02 \\
\hline \multicolumn{4}{|l|}{ Education level } \\
\hline College graduate & - & - & - \\
\hline Some college & .72 & .21 & 2.47 \\
\hline \multicolumn{4}{|l|}{ Supervisor } \\
\hline Yes & - & - & - \\
\hline No & 1.38 & .50 & 3.82 \\
\hline \multicolumn{4}{|l|}{ Model 2} \\
\hline Personal demands*personal resources & 1.00 & .99 & 1.01 \\
\hline External demands*external resources & .99 & .88 & 1.13 \\
\hline
\end{tabular}

are 1.10 times and 1.57 times more likely to report that they were very satisfied with their jobs (OR 1.10, 95\% CI 1.01, $1.20, p=.04$; OR 1.57, CI 1.26, 1.94, $p<.01)$, respectively, holding all other variables in the model constant. Model 2 examined whether the association between demands and job satisfaction varied by personal and external resources. Neither personal nor external resources significantly moderated the direct relationships between personal and external demands and job satisfaction (both $p>.45$ ).

\section{Discussion}

This study is the first, to the authors knowledge, to investigate how personal and external demands and resources faced by ECE staff who serve Head Start populations compare to normative samples (personal demands and resources) and the national workforce (external demands and resources). Framing this study using the JD-R model is novel and highlights the resources and demands that may contribute to the poor job satisfaction, turnover, and burnout experienced by this high-need population (Demerouti et al. 2001). Although the JD-R model has been applied to teachers in secondary school settings, application of this model for ECE staff is particularly innovative (Bakker et al. 2007). Overwhelmingly, these findings suggest that ECE staff experience significantly higher demands and have access to significantly fewer resources in the workplace. This imbalance may translate to poor job satisfaction, high turnover and burnout rates, and significant health disparities (Bakker and Demerouti 2017; Bauer et al. 2014). Mixed-effects models that applied the JD-R model to these data suggest that personal and external resources may have a larger impact on job satisfaction compared to personal and external demands among ECE staff. Personal and external resources, such as resilience and being treated with respect, positively and significantly impacted job satisfaction.

ECE staff within this sample reported significantly higher demands compared to normative samples (personal demands) and the national workforce (external demands). Personal demands, including depression and perceived stress, were significantly higher among ECE staff. For example, reported rates of depression in this sample were 2.3 times higher compared to nationally available normative data. These findings align with past studies that have found that the rates of depression among ECE staff are three times the national average ( $36 \%$ vs. $12 \%$ clinically depressed) (Linnan et al. 2017). Additionally, perceived stress has been found to be negatively correlated with work satisfaction among preschool teachers (Lee and Quek 2018). These personal demands may have detrimental impacts on the quality of care provided to children in ECE settings (Cumming 2017; Gratz et al. 2002; Lee and Quek 2018; Linnan et al. 2017).

This sample of ECE staff also experienced disparities related to external demands. ECE staff reported significantly higher workload and staffing concerns compared to the national workforce. In a recent study, researchers applied 
the JD-R model to examine demands among early-career teachers teaching in primary and high school settings in Finland ( $n=2038)$ (Dicke et al. 2018). Results found that high external job demands associated with teaching include work overload and a poor physical work environment. Another study, which similarly highlights this demand in the teaching profession, reported that higher job satisfaction among preschool teachers was associated with lower teacher-to-child ratios (Lee and Quek 2018). These studies support the identified external demands experienced by this sample of ECE staff; however, the findings from this sample suggest that these demands may not significantly impact job satisfaction, and potentially turnover rates, among ECE staff.

Personal resources, including resilience and mindfulness, varied between ECE staff and normative samples. Although resilience ratings were comparable between the two groups, reported mindfulness was significantly lower among ECE staff compared to normative data. A past study found that higher reported mindfulness of Head Start-funded preschool teachers was associated with lower depressive symptoms, as well as higher quality relationships with children in their care (Becker et al. 2017). A study by Garner et al. (2018) also found that an increase in mindfulness of ECE teachers resulted in an increase in emotional well-being and job satisfaction. Findings from this study suggest that there is a need to bolster mindfulness and resilience supports for this sector of the workforce to promote the job satisfaction of ECE staff and positively impact the children in their care.

This study also identified significant disparities in access to external resources, including safety climate, resource adequacy, role clarity, respect, and management relationships among ECE staff compared to the national workforce. Among preschool teachers, resource adequacy has been identified as a key job resource that contributes to overall job satisfaction. One study found that when teachers perceive more adequate resources in their work environments, they are statistically significantly more satisfied with their job (Lee and Quek 2018). Additionally, management relationship has been found to be strongly associated with job satisfaction among preschool teachers. Relationships with colleagues and management, including communication with supervisors, has been identified as a critical resource to promote job satisfaction among ECE staff (Aldridge and Fraser 2016; Lee and Quek 2018; Shen et al. 2012). Strong management relationships may also be correlated with role clarity and perceived respect, which were both identified as resources that were lacking in this sample of ECE staff.

Supervisor support was not significantly different in this sample of ECE staff compared to the national workforce based on the alpha of .01. However, $51 \%$ of this sample were supervisors which may have biased these findings and minimized the implications of these supervisory support reported data. Dicke et al. (2018) found that among primary and high school teachers, external job resources including supervisory support, access to information, innovative school climate, and social climate served as important sources of support for teachers and directly impacted burnout and overall satisfaction. Collectively, these external resources in this sample were significantly associated with increased job satisfaction, highlighting the importance of bolstering these supports in the workplace. These disparities in external resources may partially contribute to the low job satisfaction and high turnover experienced in this sample of ECE staff.

Overall, these findings highlight the disparities between ECE staff and nationally available normative samples with respect to demands and resources as well as the protective impact of personal and external resources on job satisfaction. Compassion fatigue may explain some of the elevated demands reported by this sample of ECE staff serving Head Start populations. This term originated in the fields of social work and counseling, but in more recent years has been applied to additional help-giving fields including healthcare, child protection services, and teaching (Conrad and Kellar-Guenther 2006; Peck et al. 2015). Fundamentally, ECE staff's professional requirement to support and respond to the trauma of families they serve can espouse feelings of helplessness, poor job satisfaction, and isolation (Figley 2002). These feelings of helplessness may then spill into their home life and impact their job satisfaction and overall health and well-being. ECE staff serving Head Start families are at particular risk for compassion fatigue because they serve low-income families who often experience significant adversities (Bride et al. 2007). Additional workplace-related factors associated with compassion fatigue include lack of support from administration, time constraints, and lack of autonomy (Skaalvik and Skaalvik 2009). The findings from the current study demonstrate that ECE staff disproportionately experience personal and external demands, placing them at further risk. Importantly, compassion fatigue is highly treatable. Therefore, understanding predictors of compassion fatigue and demands and resources among ECE staff is important to inform workplace policies and interventions to support this population.

Although novel, this study is not without limitations. Data from this study can only be extrapolated to ECE staff employed in: (1) Head Start-funded ECE settings, since these settings may be particularly unique and serve exclusively high-need populations, and (2) urban settings. ECE staff working in rural areas may experience additional and/ or unique demands. Additionally, a comparison group that represents a national sample of solely ECE staff did not exist. The authors recognize that comparisons to normative samples including the national workforce as reported by the GSS is limiting because employment in ECE settings represents a specific type of employment and demographic characteristics of the comparison samples may vary. There may 
also have been response bias among ECE staff who chose to complete this survey since only about half of those who were eligible completed the survey. Finally, this is a crosssectional snapshot of demands and resources experienced by ECE staff in the beginning of the school year (fall). These data may change depending on the time period of data collection (e.g., beginning or end of academic year).

\section{Conclusion}

These findings have significant implications. Although this was an exploratory study, the preliminary results suggest that ECE staff experience significantly more personal and external demands and significantly fewer personal and external resources compared to nationally available normative samples and that personal and external resources impact job satisfaction. Next steps include: (1) investigating analytically which specific external demands and resources have the greatest impact on reported job satisfaction; (2) exploring differences in reported demands and resources among ECE staff in varied ECE settings (outside of Head Start settings); and (3) the development of ECE setting-based interventions that are targeted towards mitigating identified demands and promoting identified resources for ECE staff in order to improve their job satisfaction, decrease turnover and burnout, and improve overall health and well-being of this important and disadvantaged sector of the workforce. Promoting resources and mitigating demands faced by ECE staff serving high-need populations may improve job satisfaction and overall health and well-being, in turn promoting high-quality relationships with children in their care and fostering resilience.

Funding No funding to report.

\section{Compliance with Ethical Standards}

Conflict of interest The authors declare that they have no conflict of interest.

\section{References}

Aldridge, J. M., \& Fraser, B. J. (2016). Teachers' views of their school climate and its relationship with teacher self-efficacy and job satisfaction. Learning Environments Research, 19(2), 291-307. https:// doi.org/10.1007/s10984-015-9198-x.

Bakker, A. B., \& Demerouti, E. (2017). Job demands-resources theory: Taking stock and looking forward. Journal of Occupational Health Psychology, 22(3), 273-285. https://doi.org/10.1037/ocp00 00056.

Bakker, A. B., Hakanen, J. J., Demerouti, E., \& Xanthopoulou, D. (2007). Job resources boost work engagement, particularly when job demands are high. Journal of Educational Psychology, 99(2), 274-284. https://doi.org/10.1037/0022-0663.99.2.274.

Bauer, G. F., Hämmig, O., Schaufeli, W. B., \& Taris, T. W. (2014). A critical review of the Job Demands-Resources Model: Implications for improving work and health. In Bridging occupational, organizational and public health (pp. 43-68). Dordrecht: Springer, Netherlands. https://doi.org/10.1007/978-94-007-5640-3_4.

Becker, B. D., Gallagher, K. C., \& Whitaker, R. C. (2017). Teachers' dispositional mindfulness and the quality of their relationships with children in Head Start classrooms. Journal of School Psychology, 65, 40-53. https://doi.org/10.1016/j.jsp.2017.06.004.

Blodgett, C. (2014). ACEs in head start children and impact on development. Unpublished manuscript, Child and Family Research Unit, Washington State University, Spokane, WA. Retrieved April 24, 2020 from http://ext100.wsu.edu/cafru/wp-content/uploads/ sites/65/2015/03/ACES-in-head-start-children-and-impact-ondevelopment-1-14.pdf.

Bride, B. E., Radey, M., \& Figley, C. R. (2007). Measuring compassion fatigue. Clinical Social Work Journal, 35(3), 155-163. https://doi. org/10.1007/s10615-007-0091-7.

Bright, K. A., \& Calabro, K. (1999). Child care workers and workplace hazards in the United States: Overview of research and implications for occupational health professionals. Occupational Medicine (Oxford, England), 49(7), 427-437.

Cohen, S., Kamarck, T., \& Mermelstein, R. (1983). A global measure of perceived stress. Journal of Health and Social Behavior, 24(4), 385-396. https://doi.org/10.2307/2136404.

Cohen, S., Kamarck, T., \& Mermelstein, R. (1994). Perceived stress scale. Measuring Stress: A Guide for Health and Social Scientists, $10,1-2$.

Conrad, D., \& Kellar-Guenther, Y. (2006). Compassion fatigue, burnout, and compassion satisfaction among Colorado child protection workers. Child Abuse and Neglect, 30(10), 1071-1080. https://doi. org/10.1016/j.chiabu.2006.03.009.

Cumming, T. (2017). Early childhood educators' well-being: An updated review of the literature. Early Childhood Education Journal, 45(5), 583-593. https://doi.org/10.1007/s10643-016-0818-6.

Demerouti, E., Schaufeli, W. B., \& Leuven, K. U. (2001). The Job Demands-Resources Model of Burnout The episodic nature of Work Engagement View project The Work-Home Resources Model View project. Article in Journal of Applied Psychology. https://doi.org/10.1037/0021-9010.86.3.499.

Dicke, T., Stebner, F., Linninger, C., Kunter, M., \& Leutner, D. (2018). A longitudinal study of teachers' occupational well-being: Applying the job demands-resources model. Journal of Occupational Health Psychology, 23(2), 262-277. https://doi.org/10.1037/ocp00 00070.

Figley, C. R. (2002). Compassion fatigue: Psychotherapists' chronic lack of self care. Journal of Clinical Psychology, 58(11), 14331441. https://doi.org/10.1002/jclp.10090.

Garner, P. W., Bender, S. L., \& Fedor, M. (2018). Mindfulness-based SEL programming to increase preservice teachers' mindfulness and emotional competence. Psychology in the Schools, 55(4), 377-390. https://doi.org/10.1002/pits.22114.

Gratz, R. R., Claffey, A., King, P., \& Scheuer, G. (2002). The physical demands and ergonomics of working with young children. Early Child Development and Care, 172(6), 531-537. https://doi.org/ 10.1080/03004430215109.

Harris, P. A., Taylor, R., Thielke, R., Payne, J., Gonzalez, N., \& Conde, J. G. (2009). Research electronic data capture (REDCap)-A metadata-driven methodology and workflow process for providing translational research informatics support. Journal of Biomedical Informatics, 42(2), 377-381. https://doi.org/10.1016/j. jbi.2008.08.010.

IBM SPSS Inc. (2012). SPSS statistics for windows. IBM Corp. released 2012, version 20,1-8. 
Kroenke, K., Strine, T. W., Spitzer, R. L., Williams, J. B. W., Berry, J. T., \& Mokdad, A. H. (2009). The PHQ-8 as a measure of current depression in the general population. Journal of Affective Disorders, 114(1-3), 163-173. https://doi.org/10.1016/j. jad.2008.06.026.

Lee, P. M. J., \& Quek, C. L. (2018). Preschool teachers' perceptions of school learning environment and job satisfaction. Learning Environments Research, 21(3), 369-386. https://doi.org/10. 1007/s10984-017-9256-7.

Linnan, L., Arandia, G., Bateman, L., Vaughn, A., Smith, N., \& Ward, D. (2017). The health and working conditions of women employed in child care. International Journal of Environmental Research and Public Health, 14(12), 283. https://doi.org/10. 3390/ijerph14030283.

MacKillop, J., \& Anderson, E. J. (2007). Further psychometric validation of the mindful attention awareness scale (MAAS). Journal of Psychopathology and Behavioral Assessment, 29(4), 289-293. https://doi.org/10.1007/s10862-007-9045-1.

O'Connor, A., Blewitt, C., Nolan, A., \& Skouteris, H. (2018). Using Intervention Mapping for child development and wellbeing programs in early childhood education and care settings. Evaluation and Program Planning, 68(August 2017), 57-63. https:// doi.org/10.1016/j.evalprogplan.2018.02.011.

Osman, A., Lamis, D. A., Bagge, C. L., Freedenthal, S., \& Barnes, S. M. (2016). The mindful attention awareness scale: Further examination of dimensionality, reliability, and concurrent validity estimates. Journal of Personality Assessment, 98(2), 189199. https://doi.org/10.1080/00223891.2015.1095761.

Peck, N. F., Maude, S. P., \& Brotherson, M. J. (2015). Understanding preschool teachers' perspectives on empathy: A qualitative inquiry. Early Childhood Education Journal, 43(3), 169-179. https://doi.org/10.1007/s10643-014-0648-3.

Quality of Worklife Questionnaire - NIOSH Workplace Safety and Health Topic [Internet]. Chicago, IL. U.S. Department of Health and Human Services; [updated 2018 May 15; cited 2019 January 1]. Retrieved March 24, 2018, from https://www.cdc.gov/ niosh/topics/stress/qwlquest.html.

Sharma, S., Dortch, K. S., Byrd-Williams, C., Truxillio, J. B., Rahman, G. A., Bonsu, P., \& Hoelscher, D. (2013). Nutrition-related knowledge, attitudes, and dietary behaviors among head start teachers in Texas: A cross-sectional study. Journal of the Academy of Nutrition and Dietetics, 113(4), 558-562. https://doi.org/ 10.1016/j.jand.2013.01.003.

Shen, J., Leslie, J. M., Spybrook, J. K., \& Ma, X. (2012). Are principal background and school processes related to teacher job satisfaction? A multilevel study using schools and staffing survey 2003-04. American Educational Research Journal, 49(2), 200-230. https://doi.org/10.3102/0002831211419949.

Shonkoff, J. P. (2010). Building a new biodevelopmental framework to guide the future of early childhood policy. Child Development, 81(1), 357-367. https://doi.org/10.1111/j.1467-8624. 2009.01399.x.
Shuai, J., Yue, P., Li, L., Liu, F., \& Wang, S. (2014). Assessing the effects of an educational program for the prevention of work-related musculoskeletal disorders among school teachers. BMC Public Health, 14(1), 1211. https://doi.org/10.1186/ 1471-2458-14-1211.

Skaalvik, E. M., \& Skaalvik, S. (2009). Does school context matter? Relations with teacher burnout and job satisfaction. Teaching and Teacher Education, 25(3), 518-524. https://doi.org/10. 1016/j.tate.2008.12.006.

Smith, B. W., Dalen, J., Wiggins, K., Tooley, E., Christopher, P., \& Bernard, J. (2008). The brief resilience scale: Assessing the ability to bounce back. International Journal of Behavioral Medicine, 15(3), 194-200. https://doi.org/10.1080/1070550080 2222972.

Smith, T. W., Davern, M., Freese, J., \& Morgan, S. L. (2019). General Social Surveys, 1972-2018 [machine-readable data file]. Chicago: NORC.

Torquati, J. C., Raikes, H., \& Huddleston-Casas, C. A. (2007). Teacher education, motivation, compensation, workplace support, and links to quality of center-based child care and teachers' intention to stay in the early childhood profession. Early Childhood Research Quarterly, 22(2), 261-275. https://doi.org/10.1016/J. ECRESQ.2007.03.004.

Totenhagen, C. J., Hawkins, S. A., Casper, D. M., Bosch, L. A., Hawkey, K. R., \& Borden, L. M. (2016). Retaining early childhood education workers: A review of the empirical Literature. Journal of Research in Childhood Education, 30(4), 585-599. https://doi.org/10.1080/02568543.2016.1214652.

Vasilopoulos, T., Morey, T. E., Dhatariya, K., \& Rice, M. J. (2016). Limitations of significance testing in clinical research: A review of multiple comparison corrections and effect size calculations with correlated measures. Anesthesia \& Analgesia, 122(3), 825-830.

Wells, M. B. (2015). Predicting preschool teacher retention and turnover in newly hired Head Start teachers across the first half of the school year. Early Childhood Research Quarterly, 30, 152-159. https://doi.org/10.1016/J.ECRESQ.2014.10.003.

Whitaker, R. C., Becker, B. D., Herman, A. N., \& Gooze, R. A. (2013). The physical and mental health of Head Start staff: The Pennsylvania Head Start staff wellness survey, 2012. Preventing Chronic Disease, 10, E181. https://doi.org/10.5888/pcd10.130171.

Whitebook, M., McLean, C., \& Austin, L. J. E. (2016). Early Childhood Workforce INDEX. Center for the Study of Child Care Employment Institute for Research on Labor and Employment University of California, Berkeley A, (Early Childhood Workforce), 120.

Publisher's Note Springer Nature remains neutral with regard to jurisdictional claims in published maps and institutional affiliations. 